\author{
Jarosław TATARCZAK ${ }^{1}$ \\ Marta SOKOLOWSKA ${ }^{2}$ \\ Jan M. OLCHOWIK ${ }^{3}$
}

\title{
ANALIZA NAPROMIENIOWANIA \\ SŁONECZNEGO POLSKI NA PODSTAWIE DANYCH SATELITARNYCH NASA
}

\begin{abstract}
Napromieniowanie określa sumę energii promieniowania słonecznego jaka pada na określoną powierzchnię $\mathrm{w}$ danym przedziale czasu. Dzięki tej wielkości fizycznej człowiek jest w stanie określić zasoby energii słonecznej w danym czasie i miejscu. Jest to istotne zwłaszcza dla takich branż jak rolnictwo, budownictwo czy energetyka, gdzie ma pośrednie lub bezpośrednie przełożenie na finanse. Napromieniowanie jest wartością pozornie łatwą od zmierzenia, wystarczy do tego odpowiednia aparatura pomiarowa. Problem pojawia się jednak gdy pomiary obejmują znaczy obszar a urządzenia mierzące są często nie skalibrowane w odpowiedni sposób. Wydaje się więc, że najlepszym rozwiązaniem było stosowanie jednego typu urządzeń, połączonych ze sobą specjalną siecią informacyjną. Rozwiązaniem może być pomiar dokonywany przez satelity krążące wokół kuli ziemskiej. W niniejszej pracy podjęto próbę określenia warunków nasłonecznienia Polski, sporządzając analizę, wykorzystującą bazę danych, opartą na ponad 20-letniej rejestracji promieniowania słonecznego na świecie przez system satelitarny, w ramach projektu NASA: „Surface Meteorology and Solar Energy (SSE)".Pomiary mają rozdzielczość jednego stopnia szerokości i długości geograficznej. Obliczenia i ich metodologia zawarte w artykule pozwoliły na opracowanie topologii nasłonecznienia dla wybranych szerokości geograficznych naszego kraju. Wyniki analizy przedstawiono w formie graficznej. Wyniki przeprowadzonej analizy mogą służyć pomocą w procesie planowania inwestycji energetyki słonecznej na terenie Polski.
\end{abstract}

Słowa kluczowe: fotowoltaika, algorytm, promieniowanie dyfuzyjne, energia słoneczna

\footnotetext{
${ }^{1}$ Jarosław Tatarczak, Uniwersytet Przyrodniczy w Lublinie, Katedra Maszyn Ogrodniczych i Leśnych, ul. Głęboka 28, 20-612 Lublin, +48 8153196 53, jaroslaw.tatarczak@gmail.com

${ }^{2}$ Marta Sokołowska, Studenckie Koło Naukowe Energetyki Odnawialnej „GRUPA OGNIWO”, Wydział Inżynierii Środowiska, Politechnika Lubelska

${ }^{3}$ Autor do korespondencji/corresponding author: Jan M. Olchowik, Politechnika Lubelska, Instytut Inżynierii Odnawialnych Źródeł Energii, ul. Nadbystrzycka 40B, 20-618 Lublin, +48 81538 4700, j.olchowik@pollub.pl
} 


\section{Wstęp}

Efektywne zagospodarowanie promieniowania słonecznego na Ziemi na cele użyteczne zależy silnie od jego charakterystyki na konkretnej szerokości geograficznej. Chodzi tu głównie o nasłonecznienie i usłonecznienie. Wiarygodność tych danych wynika przede wszystkim ze sposobu i warunków rejestracji tego promieniowania. Stacje pomiarowe wykorzystują różne detektory, w wyniku czego nie posiadają wspólnego punktu odniesienia (wspólnej kalibracji). W niniejszej pracy podjęto próbę określenia warunków nasłonecznienia Polski, wykorzystując bazę danych, opartą na ponad 20 letniej rejestracji promieniowania słonecznego nad Polską przez system satelitarny NASA.

\section{Baza danych}

W ramach naukowego programu badań Ziemi, NASA od dawna dostarcza istotnych danych klimatycznych pochodzących z satelitów krążących wokół Ziemi. Dane te obejmują długoterminowe szacunkowo-ilościowe dane o przepływie energii słonecznej na powierzchni Ziemi. Dostarczane dane są na tyle dokładne i niezawodne by objąć takie obszary, gdzie pomiary dokonywane są rzadko lub wcale. Baza danych „Surface Meteorology and Solar Energy (SSE)", dotycząca warunków klimatycznych jest dostępna na stronie internetowej należącej do NASA [1].

Obecnie dostępne są dane meteorologiczne w wersji 6.0 (SSE-Release 6.0), opublikowane w 2008 roku. Obejmują one okres od 1 lipca 1983 do 30 czerwca 2005r., co daje 22 lata pomiarów [1]. Baza danych zawiera 200 różnych parametrów meteorologicznych, opracowanych na podstawie pomiarów satelitarnych. Rozdzielczość tych pomiarów to 1 stopień szerokości i długości geograficznej. Daje to 64800 punktów pomiarowych na całym globie. Wyniki pomiarów przedstawiane są jako średnie dzienne wartości dla poszczególnych miesięcy roku [2].

\section{Dokładność pomiarów}

Zasadniczo dane dostarczane $\mathrm{z}$ naziemnych stacji meteorologicznych są bardziej dokładne. Jednak niepewność pomiarów, spowodowana nieprawidłową kalibracją urządzeń czy brakiem danych (luka w pomiarach) w naziemnych stacjach pomiarowych nie jest zawsze zgłaszana. Według szacunków „World Climate Research Programme" z 1989, niepewność pomiarowa naziemnych stacji wynosiła 6-12\% [1]. Szacunkowe dane SSE zostały porównane z danymi naziemnych stacji pomiarowych - Baseline Surface Radiation Network (BSRN), w skali globalnej [1,2] i przedstawione w tabeli poniżej: 
Tabela 1. Analiza regresji danych z SSE i BSRN, średnich miesięcznych wartości w okresie od lipca 1983 do czerwca 2006, na podstawie [1,2]

Table 1. Regression analysis of data which is based on the SSE and BSRN for average monthly value in the period from July 1983 to June 2006, based on [1,2]

\begin{tabular}{|l|l|r|r|}
\hline Parametr & Strefa & Bias (\%) & RMSE (\%) \\
\hline \multirow{3}{*}{$\begin{array}{l}\text { Nasłonecznienie na powierzchnię } \\
\text { horyzontalną }\end{array}$} & Globalnie & $-0,01$ & 10,25 \\
\cline { 2 - 4 } & Powyżej +/- $60^{\circ} \mathrm{N} / \mathrm{S}$ & $-1,18$ & 34,37 \\
\cline { 2 - 4 } & Poniżej +/- $60^{\circ} \mathrm{N} / \mathrm{S}$ & 0,29 & 8,71 \\
\hline \multirow{3}{*}{$\begin{array}{l}\text { Promieniowanie rozproszone na } \\
\text { powierzchnię horyzontalną }\end{array}$} & Globalnie & 7,49 & 29,34 \\
\cline { 2 - 4 } & Powyżej +/- $60^{\circ} \mathrm{N} / \mathrm{S}$ & 11,29 & 54,14 \\
\cline { 2 - 4 } & Poniżej +/- $60^{\circ} \mathrm{N} / \mathrm{S}$ & 6,86 & 22,78 \\
\hline \multirow{3}{*}{$\begin{array}{l}\text { Promieniowanie bezpośrednie na } \\
\text { powierzchnię normalną }\end{array}$} & Globalnie & $-4,06$ & 22,73 \\
\cline { 2 - 4 } & Powyżej $+/-60^{\circ} \mathrm{N} / \mathrm{S}$ & $-15,66$ & 33,12 \\
\cline { 2 - 4 } & Poniżej $+/-60^{\circ} \mathrm{N} / \mathrm{S}$ & 2,4 & 20,93 \\
\hline
\end{tabular}

\section{Metodyka obliczania parametrów ekspozycji promieniowa- nia słonecznego na wybrany obszar Ziemi}

\subsection{Deklinacja}

Deklinacja jest kątowym odchyleniem pozycji Słońca podczas słonecznego południa, w odniesieniu do płaszczyzny równika. Równanie Copper'a, pozwalające obliczyć tą wartość (w stopniach) przedstawiono poniżej [1, 3, 4]:

$$
\delta=23,45 \sin \left(2 \pi \frac{284+\mathrm{n}}{365}\right)
$$

gdzie: $\quad \delta$-deklinacja pozycji słońca,

$\mathrm{n}$ - kolejny dzień roku.

Wartość deklinacji waha się, w ciągu roku, w granicach od $+23,45^{\circ}$ (21 czerwiec) do $-23,45^{\circ}$ (21 grudzień). Dla obliczeń wykorzystano średnią miesięczną wartość deklinacji przedstawioną w Tabeli 2 [1]. 
Tabela 2. Średnia miesięczna wartość deklinacji

Table 2. Average monthly value of declination

\begin{tabular}{|l|r|r|r|}
\hline Miesiąc & $\begin{array}{r}\text { Dzień } \\
\text { miesiąca }\end{array}$ & $\begin{array}{r}\text { Dzień } \\
\text { roku }\end{array}$ & $\boldsymbol{\delta}\left(^{(\boldsymbol{})}\right.$ \\
\hline Styczeń & 17 & 17 & -20.9 \\
\hline Luty & 16 & 47 & -13.0 \\
\hline Marzec & 16 & 75 & -2.4 \\
\hline Kwiecień & 15 & 105 & 9.4 \\
\hline Maj & 15 & 135 & 18.8 \\
\hline Czerwiec & 11 & 162 & 23.1 \\
\hline Lipiec & 17 & 198 & 21.2 \\
\hline Sierpień & 16 & 228 & 13.5 \\
\hline Wrzesień & 15 & 258 & 2.2 \\
\hline Październik & 15 & 288 & -9.6 \\
\hline Listopad & 14 & 318 & -18.9 \\
\hline Grudzień & 10 & 344 & -23.0 \\
\hline
\end{tabular}

\subsection{Godzinowy kąt słoneczny i godzinowy kąt zachodu słońca}

Godzinowy kąt słoneczny ( $\omega)$, jest to kąt odchylenia słońca na wschód lub zachód od lokalnego południka. Kąt ten jest równy zero w czasie południa słonecznego, ujemny przed południem i dodatni po południu. Godzina słoneczna odpowiada kątowi $15^{\circ}$ [3]. Godzinowy kąt zachodu słońca $\left(\omega_{\mathrm{s}}\right)$, odpowiadający wartości godzinowego kąta słonecznego w porze zachodu słońca, wyraża się następująco [3]:

$$
\cos \left(\omega_{\mathrm{s}}\right)=-\tan (\varphi) \tan (\delta),
$$

gdzie: $\omega_{\mathrm{s}}-$ godzinowy kąt zachodu słońca,

$\varphi$ - szerokość geograficzna, $\delta$ - deklinacja.

W przypadku dokonywania obliczeń w programach kalkulacyjnych (np. Microsoft Excel) należy zamienić wartość kątową na radiany. 


\subsection{Promieniowanie słoneczne powyżej granicy atmosfery}

Promieniowanie poza atmosferą ziemską $\left(\mathrm{H}_{0}\right)$, na jednostkę powierzchni (horyzontalną) określa, ile energii słonecznej dociera na zewnątrz atmosfery Ziemi. Tę wartość można obliczyć korzystając ze wzoru [5]:

$$
\begin{aligned}
& \mathrm{H}_{0}=\int_{\omega_{\text {wsch }}}^{\omega_{\text {wach }}} G_{S C}\left(1+0,033 \cos \left(360 \frac{\mathrm{n}}{365}\right)\right) \cdot[\cos (\varphi) \cos (\delta) \cos (\omega)+ \\
& \sin (\varphi) \sin (\delta)] d \omega,
\end{aligned}
$$

gdzie: $\quad \mathrm{H}_{0}$ - promieniowanie słoneczne poza atmosferą ziemską, $\mathrm{G}_{\mathrm{sc}}$ - stała słoneczne - wynosząca $1367 \mathrm{~W} / \mathrm{m}^{2}, \mathrm{n}$ - kolejny dzień roku, $\varphi$ - szerokość geograficzna, $\delta$ - deklinacja, $\omega$ - godzinowy kąt słoneczny.

Założono, że: $\omega_{\text {wsch }}=\omega_{\text {zach }}=\omega_{\mathrm{s}}$. Zatem, nasłonecznienie dzienne dla powierzchni horyzontalnej znajdującej się na zewnątrz atmosfery, wynosi [4,5]:

$$
\begin{aligned}
& \mathrm{H}_{0}=\frac{86400}{\pi} \mathrm{G}_{\mathrm{SC}}\left(1+0,033 \cos \left(360 \frac{\mathrm{n}}{365}\right)\right) . \\
& {\left[\cos (\varphi) \cos (\delta) \sin \left(\left|\omega_{\mathrm{s}}\right|\right)+\left|\omega_{\mathrm{s}}\right| \sin (\varphi) \sin (\delta)\right] .}
\end{aligned}
$$

Po scałkowaniu promieniowania $\mathrm{H}_{0}$, uzyskuje się wynik wyrażony $\mathrm{w} \mathrm{J} / \mathrm{m}^{2}$. Aby przeliczyć tę wartość na $\mathrm{kWh} / \mathrm{m}^{2}$, wynik należy przemnoży przez $3,6 \cdot 10^{-6}$. Podobnie można określić średnie miesięczne nasłonecznienie poza granicą atmosfery $\overline{\mathrm{H}}_{0}$.

\subsection{Wskaźnik przejrzystości atmosfery}

Wskaźnik przejrzystości atmosfery (K) określa, jaka część promieniowania dociera do powierzchni Ziemi. Dla obliczeń i prezentacji danych, wskaźnik $\overline{\mathrm{K}}$, odnosi się do średnich miesięcznych wartości i przedstawiony jest wyrażeniem $[1,3,4,5]$ :

$$
\bar{K}=\frac{\overline{\mathrm{H}}}{\overline{\mathrm{H}}_{0}},
$$

gdzie: $\quad \bar{K}-$ średni miesięczny wskaźnik przejrzystości atmosfery,

$\overline{\mathrm{H}}$ - średnie miesięczne promieniowanie na powierzchnię horyzontalną przy gruncie $\left[\mathrm{kWh} / \mathrm{m}^{2}\right], \overline{\mathrm{H}}_{0}$ - średnie miesięczne promieniowanie na powierzchnię horyzontalną poza granicą atmosfery $\left[\mathrm{kWh} / \mathrm{m}^{2}\right]$.

Średnie miesięczne wartości przedstawionego wskaźnika, są zależne od lokalizacji i pory roku. Wahają się one od 0,3 (duże miesięczne zachmurzenie), do 0,8 (duża miesięczna przejrzystość powietrza) [3,4]. 


\subsection{Współczynnik składowej rozproszonej do całkowitego nasłonecznienia}

Średnia miesięczna wartość współczynnika składowej rozproszonej do całkowitej nasłonecznienia $\frac{\overline{\mathrm{H}}_{\mathrm{d}}}{\overline{\mathrm{H}}}$ może zostać wyznaczona za pomocą następujących równań [1]:

Dla szerokości geograficznych w granicach od $45^{\circ} \mathrm{S}$ do $45^{\circ} \mathrm{N}$ :

$\frac{\overline{\mathrm{H}}_{\mathrm{d}}}{\overline{\mathrm{H}}}=0,96268-(1,45200 \cdot \mathrm{K})+\left(0,27365 \cdot \mathrm{K}^{2}\right)+\left(0,04279 \cdot \mathrm{K}^{3}\right)+$ $\left(0,000246 \cdot \omega_{s}\right)+\left(0,001189 \cdot \alpha_{n}\right) ;$

Dla szerokości geograficznych w granicach poniżej $45^{\circ} \mathrm{S}$ i powyżej $45^{\circ} \mathrm{N}$ :

- $\operatorname{przy} 0^{\circ} \leq \omega_{\mathrm{s}} \leq 81,4^{\circ}$ :

$\frac{\overline{\mathrm{H}}_{\mathrm{d}}}{\overline{\mathrm{H}}}=1,441-(3,6839 \cdot \mathrm{K})+\left(6,4927 \cdot \mathrm{K}^{2}\right)-\left(4,147 \cdot \mathrm{K}^{3}\right)+$ $\left(0,0008 \cdot \omega_{\mathrm{s}}\right)-\left(0,008175 \cdot \alpha_{\mathrm{n}}\right) ;$

- $\operatorname{przy} 81,4^{\circ}<\omega_{\mathrm{s}} \leq 100^{\circ}$ :

$\frac{\overline{\mathrm{H}}_{\mathrm{d}}}{\overline{\mathrm{H}}}=1,6821-(2,5866 \cdot \mathrm{K})+\left(2,373 \cdot \mathrm{K}^{2}\right)-\left(0,5294 \cdot \mathrm{K}^{3}\right)-$

$\left(0,00277 \cdot \omega_{\mathrm{s}}\right)-\left(0,004233 \cdot \alpha_{\mathrm{n}}\right)$;

- $\operatorname{przy} 100^{\circ}<\omega_{\mathrm{s}} \leq 125^{\circ}$ :

$\frac{\overline{\mathrm{H}}_{\mathrm{d}}}{\overline{\mathrm{H}}}=0,3498+(3,8035 \cdot \mathrm{K})-\left(11,765 \cdot \mathrm{K}^{2}\right)+\left(9,1748 \cdot \mathrm{K}^{3}\right)+$ $\left(0,001575 \cdot \omega_{s}\right)-\left(0,002837 \cdot \alpha_{n}\right)$;

- $\operatorname{przy} 125^{\circ}<\omega_{\mathrm{s}} \leq 150^{\circ}$ :

$\frac{\overline{\mathrm{H}}_{\mathrm{d}}}{\overline{\mathrm{H}}}=1,6586-(4,412 \cdot \mathrm{K})+\left(5,8 \cdot \mathrm{K}^{2}\right)-\left(3,1223 \cdot \mathrm{K}^{3}\right)+$

$\left(0,000144 \cdot \omega_{s}\right)-\left(0,000829 \cdot \alpha_{n}\right)$;

- $\operatorname{przy} 150^{\circ}<\omega_{\mathrm{s}} \leq 180^{\circ}$ :

$\frac{\overline{\mathrm{H}}_{\mathrm{d}}}{\overline{\mathrm{H}}}=0,6563-(2,893 \cdot \mathrm{K})+\left(4,594 \cdot \mathrm{K}^{2}\right)-\left(3,23 \cdot \mathrm{K}^{3}\right)+$ $\left(0,004 \cdot \omega_{s}\right)-\left(0,0023 \cdot \alpha_{n}\right)$,

gdzie: $\frac{\bar{H}_{d}}{\overline{\mathrm{H}}}-$ współczynnik składowej rozproszonej do całkowitego promieniowanie, $\omega_{\mathrm{s}}$ - godzinowy kąt zachodu słońca, $\alpha_{\mathrm{n}}$ - kąt wysokości słońca w południe (w radianach). 
Kąt wysokości słońca $\mathrm{w}$ porze południowej, dla średniej miesięcznej wartości deklinacji (Tabela 2.) można obliczyć z następującej zależności:

$$
\alpha_{\mathrm{n}}=(90-(\varphi-\delta))
$$

gdzie: $\quad \alpha_{\mathrm{n}}-$ kąt wysokości słońca,

$\varphi$ - szerokość geograficzna, $\delta$ - deklinacja.

\subsection{Składowa rozproszona i bezpośrednia promieniowania słonecznego na powierzchnię horyzontalną}

Całkowite średnie nasłonecznie $\overline{\mathrm{H}}$ jest wartością, pozyskaną $\mathrm{z}$ baz danych SSE. Średnią miesięczną składową rozproszoną $\overline{\mathrm{H}}_{\mathrm{d}}$ można wyznaczyć ze wzoru:

$$
\overline{\mathrm{H}}_{\mathrm{d}}=\overline{\mathrm{H}} \cdot \frac{\overline{\mathrm{H}}_{\mathrm{d}}}{\overline{\mathrm{H}}} .
$$

Średnią miesięczną składową bezpośrednią promieniowania słonecznego $\overline{\mathrm{H}}_{\mathrm{b}}$ padającą na powierzchnię horyzontalną można określić, jako:

$$
\overline{\mathrm{H}}_{\mathrm{b}}=\overline{\mathrm{H}}-\overline{\mathrm{H}}_{\mathrm{d}} .
$$

\section{7. Średnie dzienne promieniowanie słoneczne na powierzchnię pochyłą}

Poniżej została przedstawiona metoda obliczania nasłonecznienia na powierzchnię nachyloną pod kątem $\mathrm{z}$ zakresu od $0^{\circ}$ do $90^{\circ}$, skierowaną w kierunku południowym. Na początku należy określić promieniowanie całkowite $\mathrm{H}_{\mathrm{h}}$, rozproszone $\mathrm{H}_{\mathrm{hd}} \mathrm{i}$ bezpośrednie $\mathrm{H}_{\mathrm{hb}}$ w poszczególnych godzinach dnia $[1,3,4,5]$ :

$$
\begin{aligned}
& \mathrm{H}_{\mathrm{h}}=\mathrm{r}_{\mathrm{t}} \cdot \overline{\mathrm{H}}, \\
& \mathrm{H}_{\mathrm{hd}}=\mathrm{r}_{\mathrm{d}} \cdot \overline{\mathrm{H}}_{\mathrm{d}}, \\
& \mathrm{H}_{\mathrm{hb}}=\mathrm{H}_{\mathrm{h}}-\mathrm{H}_{\mathrm{hd}},
\end{aligned}
$$

gdzie: $r_{d}$ - współczynnik korekcyjny Collares-Pereira i Rabl'a, dla poszczególnej godziny dnia , $\mathrm{r}_{\mathrm{d}}$ - współczynnik korekcyjny Liu i Jordan'a, dla poszczególnej godziny dnia.

Współczynnik korekcyjny $r_{t}$ jest wymagany do obliczenia napromieniowanie całkowanego godzinowego (15). Można go wyznaczyć z zależności przedstawionych poniżej:

$$
r_{t}=\frac{\pi}{24}[a+b \cdot \cos (\omega)] \frac{\cos (\omega)-\cos \left(\omega_{s}\right)}{\sin (\omega)-\omega_{s} \cdot \cos \left(\omega_{s}\right)^{\prime}}
$$




$$
\begin{aligned}
& a=0,409+0,5016 \cdot \sin \left(\omega_{s}-\frac{\pi}{3}\right), \\
& b=0,6609-0,4767 \cdot \sin \left(\omega_{s}-\frac{\pi}{3}\right),
\end{aligned}
$$

gdzie: $\omega$ - godzina kątowa (w radianach), $\omega_{\mathrm{s}}$ - godzinowy kąt zachodu słońca (w radianach).

Współczynnik korekcyjny $r_{d}$ jest wymagany do obliczenia napromieniowanie rozproszonego godzinowego (wyrażenie 16). Współczynnik ten można wyznaczyć z zależności przedstawionych poniżej $[1,3,4,5]$ :

$$
r_{d}=\frac{\pi}{24} \frac{\cos (\omega)-\cos \left(\omega_{s}\right)}{\sin (\omega)-\omega_{s} \cdot \cos \left(\omega_{s}\right)}
$$

gdzie: $\omega$ - godzina kątowa (w radianach), $\omega_{\mathrm{s}}$ - godzinowy kąt zachodu słońca (w radianach).

Współczynnik korekcyjny $\mathrm{R}_{\mathrm{b}}$ jest wymagany, by skorygować bezpośrednie napromieniowanie nachylonej powierzchni. Współczynnik ten można wyznaczyć następująco $[4,5]$ :

$$
\begin{aligned}
& \mathrm{R}_{\mathrm{b}}=\frac{\cos (\theta)}{\cos \left(\theta_{\mathrm{z}}\right)}, \\
& \cos \left(\theta_{\mathrm{z}}\right)=\cos (\varphi) \cos (\delta) \cos (\omega)+\sin (\varphi) \sin (\delta), \\
& \cos (\theta)=\cos (\varphi-\beta) \cos (\delta) \cos (\omega)+\sin (\varphi-\beta) \sin (\delta),
\end{aligned}
$$

gdzie: $\varphi$ - szerokość geograficzna, $\delta$ - deklinacja, $\omega$ - godzina kątowa (w radianach), $\beta$ - kąt nachylenia powierzchni względem Ziemi.

Godzinowa wartość całkowitego $H_{h t}$ napromieniowanie, na nachyloną powierzchnię może być wyznaczona w następujący sposób:

$$
H_{h t}=\mathrm{H}_{\mathrm{b}} \mathrm{R}_{\mathrm{b}}+\mathrm{H}_{\mathrm{d}}\left(\frac{1+\cos (\beta)}{2}\right)+H \rho\left(\frac{1-\cos (\beta)}{2}\right),
$$

gdzie: $\beta$ - kąt nachylenia powierzchni względem Ziemi, $\rho$ - współczynnik albedo, parametr ten określa zdolność odbijania promieni od danej powierzchni.

Współczynnik albedo $(\rho)$ można wyliczyć także na podstawie średniej temperatury w ciągu miesiąca. Jeżeli temperatura otoczenia jest powyżej $0^{\circ} \mathrm{C}$, to wartość $\rho=0.2$, a jeżeli temperatura jest poniżej $-5^{\circ} \mathrm{C}$, to $\rho=0,7$. Dla temperatur pomiędzy $-5^{\circ} \mathrm{C}$ i $0^{\circ} \mathrm{C}$ wartość albedo $(\rho)$ zmienia się w sposób liniowy $[1,3]$. 
Tabela 3. Średnie wartości współczynnika albedo $(\rho)$ dla charakterystycznych powierzchni, na podstawie [6]

Table 3. Average values of albedo( $\rho)$ for a given characteristic kind of surface, based on [6]

\begin{tabular}{|r|l|r|}
\hline Lp. & Rodzaj powierzchni & $\begin{array}{r}\text { Wartość } \\
\text { albedo }\end{array}$ \\
\hline 1. & Śnieg (świeży) & 0,75 \\
\hline 2. & $\begin{array}{l}\text { Lustro wody (duży kąt } \\
\text { padania) }\end{array}$ & 0,07 \\
\hline 3. & Ziemia (gliniasta) & 0,14 \\
\hline 4. & Las iglasty (zimą) & 0,07 \\
\hline 5. & $\begin{array}{l}\text { Las jesienią, dojrzałe } \\
\text { pola zbóż, plantacje }\end{array}$ & 0,26 \\
\hline 6. & Płaszczyzna asfaltowa & 0,10 \\
\hline 7. & Płaszczyzna betonowa & 0,22 \\
\hline 8. & Opadłe liście & 0,30 \\
\hline 9. & Wyschnięta trawa & 0,20 \\
\hline 10. & Zielona trawa & 0,26 \\
\hline
\end{tabular}

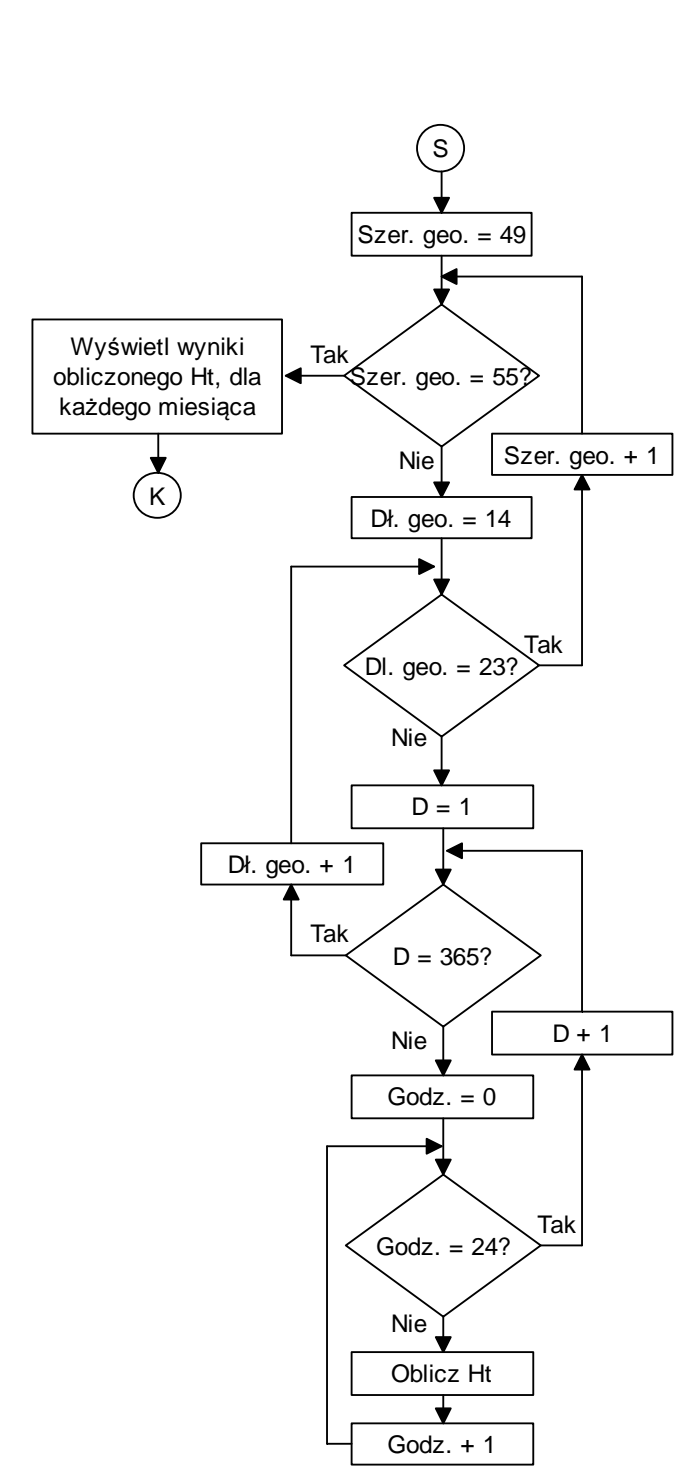

Średnia miesięczna wartość napromieniowania $\left(\bar{H}_{t}\right)$ jest szacowana na podstawie sumowaniu wartości godzinowych napromieniowania na nachyloną powierzchnię $\left(H_{h t}\right)$. Algorytm wyznaczania średnio - miesięcznej wartości napromieniowania na pochyłą powierzchnię przedstawiony jest na Rys. 1.

Rys. 1. Algorytm wyznaczania średniej miesięcznej wartości napromieniowania na pochyłą powierzchnię, dla obszaru Polski (od $14^{\circ} \mathrm{E}$ do $23^{\circ} \mathrm{E}$ oraz od $49^{\circ} \mathrm{N}$ do $55^{\circ} \mathrm{N}$ ). S - początek algorytmu, $\mathrm{K}$ - koniec algorytmu

Fig. 1. The algorithm for calculating the average monthly irradiation on an inclined surface in Poland (from $14^{\circ} \mathrm{E}$ to $23^{\circ} \mathrm{E}$ and from $49^{\circ} \mathrm{N}$ to $55^{\circ} \mathrm{N}$ ). S - the beginning of the algorithm, $\mathrm{K}$ - the end of the algorithm 


\section{Wyniki}

Wyniki obliczeń przedstawione zostały na rysunkach Rys. 2-9.

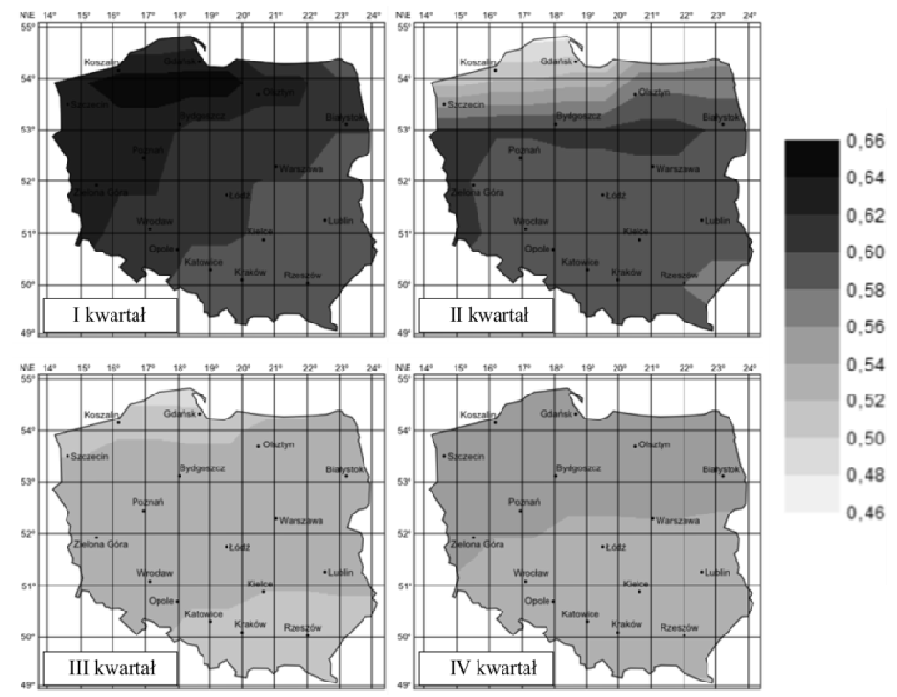

Rys. 2. Średnia kwartalna wartość składowej dyfuzyjnej do całkowitej energii promieniowania słonecznego dla terenu Polski $(1.0=100 \%)$

Fig. 2: Average quarterly value of the diffusion in relation to the total solar energy radiation in Poland $(1.0=100 \%)$

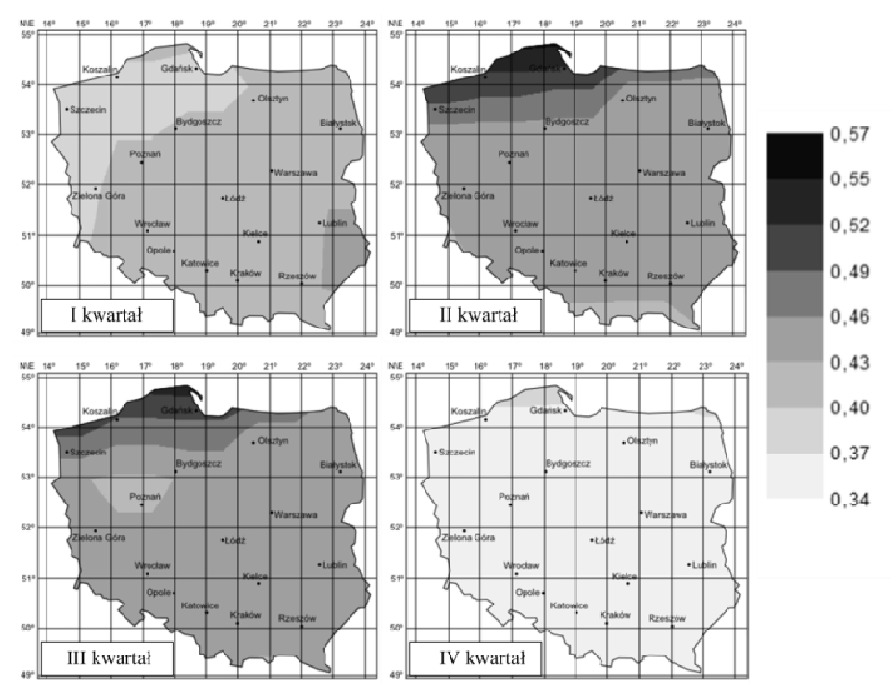

Rys. 3. Średni kwartalny wskaźnik przejrzystości powietrza dla terenu Polski $(1.0=100 \%$ przejrzystości powietrza)

Fig. 3. Average quarterly clearness index of air mass in Poland $(1.0=100 \%$ transparency of air $)$ 

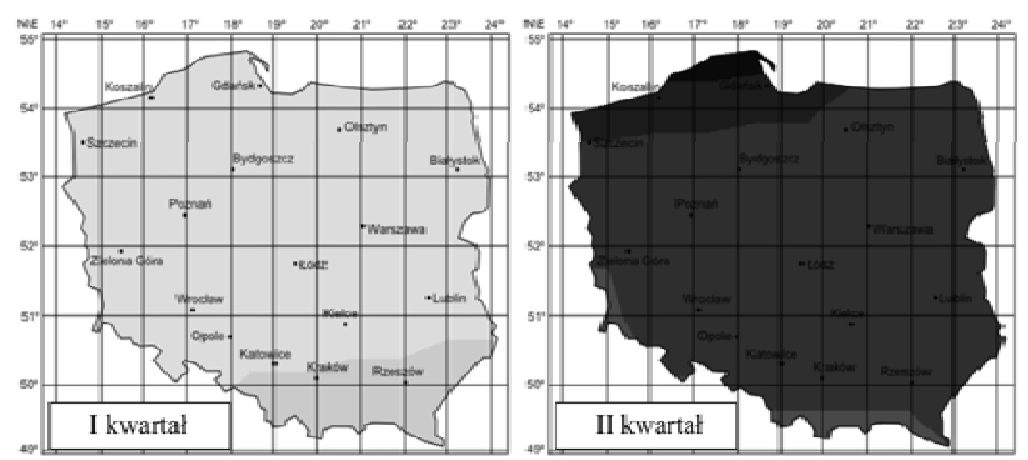

kWh 172 kisartill
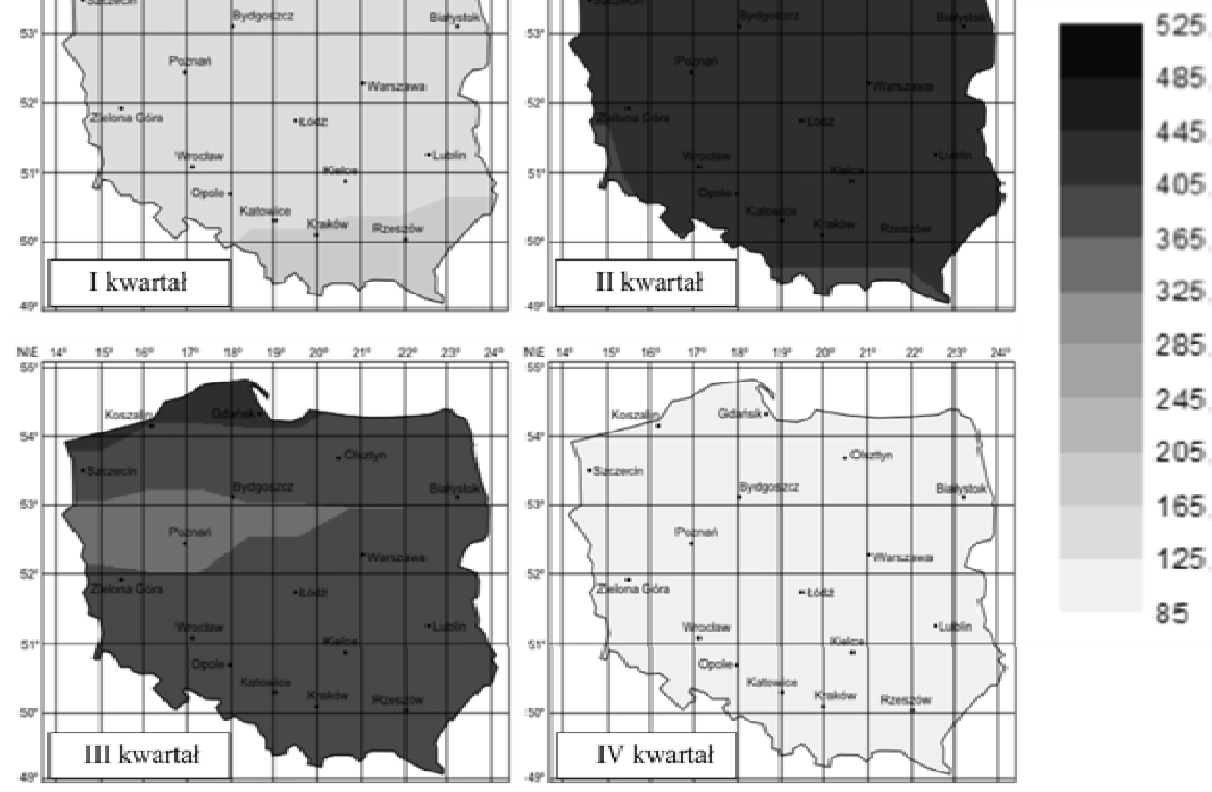

285

245

205

165

125

85

Rys. 4. Kwartalne napromieiowanie dla terenu Polski na powierzchnię horyzontalną

Fig. 4. Quarterly irradiation on a horizontal surface in Poland 

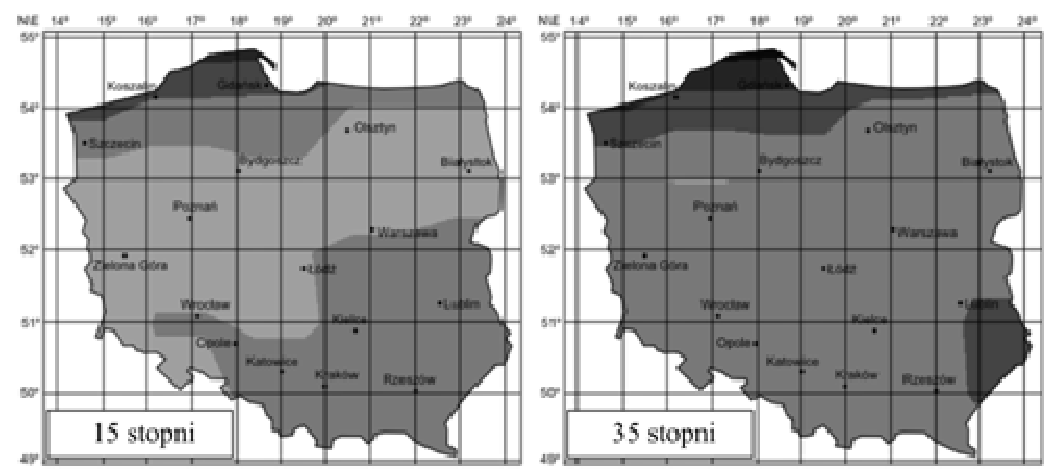

6 Why
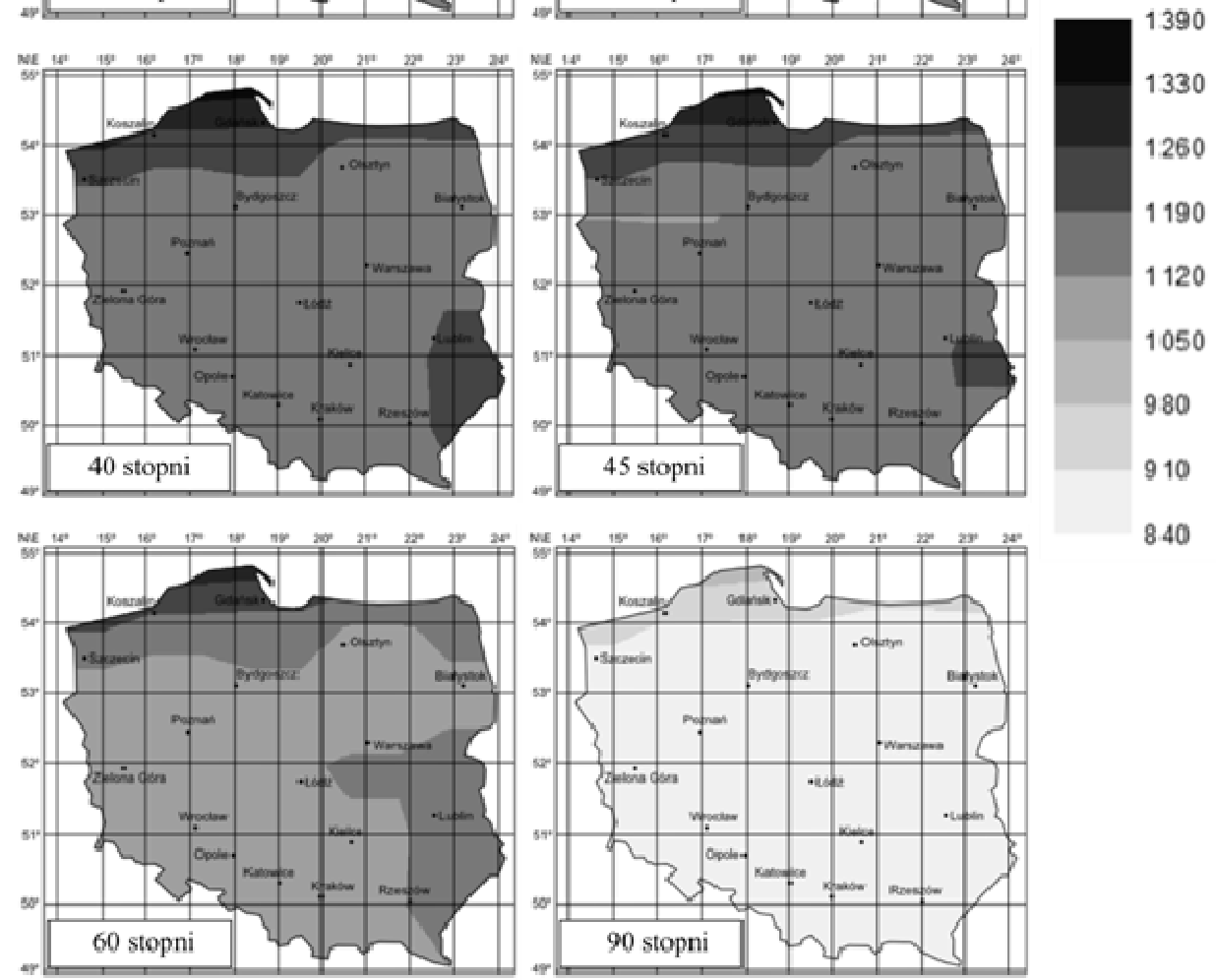

840

Rys. 5. Roczne napromieniowanie dla terenu Polski na płaszczyznę nachyloną o wybrany kąt względem ziemi

Fig. 5. Annual irradiation for Poland on the inclined plane for selected angles of inclination in relation to the ground 

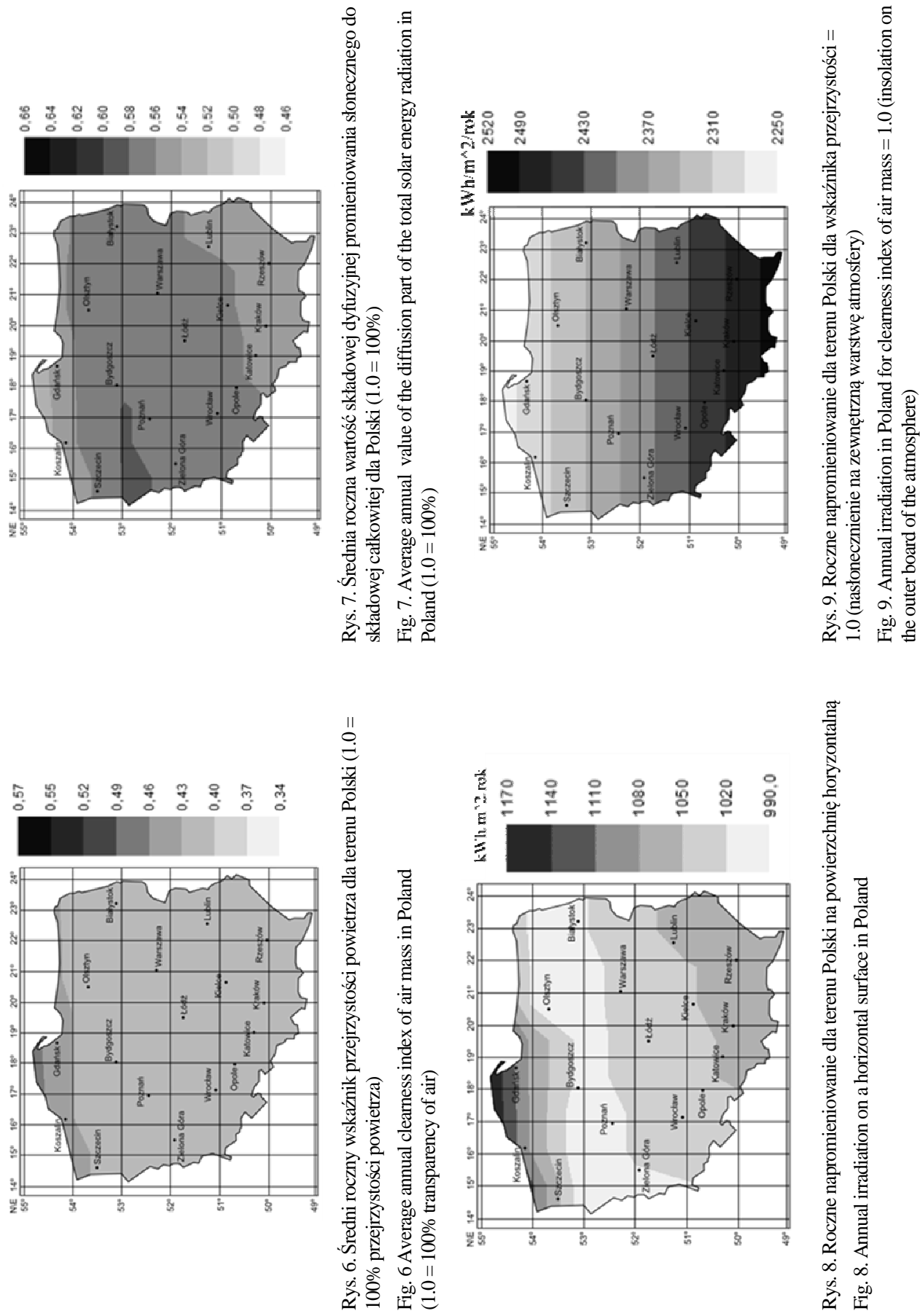


\section{Podsumowanie}

Wykorzystanie bazy danych „Surface Meteorology and Solar Energy (SSE)” NASA, może być pomocne przy projektowaniu i ocenie efektywności konwerterów energii słonecznej w energię użyteczną. Długookresowe dane, uzyskane z jednego źródła przy zastosowaniu tej samej metodologii rejestracji stanowią wiarygodne źródło do stworzenie topologii nasłonecznienia na wybranej szerokości geograficznej. Uwidocznienie tych danych w różnych sekwencjach czasowych pozwala optymalizować projekt inwestycji energetyki słonecznej.

\section{Literatura:}

[1] Surface meteorology and Solar Energy (SSE) Release 6.0 Methodology Version 3.1.1, January 2013.

[2] Strona internetowa bazy danych SSE Realsed 6.0: http://eosweb.larc.nasa.gov/sse/.

[3] Clean Energy Project Analysis, RETScreen ${ }^{\circledR}$ Engineering \& Cases Textbook Third Edition, Kanada, September 2005.

[4] Duffi'e, J.A. and Beckman, W.A., Solar Engineering of Thermal Processes, 3nd Edition, John Wiley\& Sons, 1991.

[5] Jastrzębska G., Odnawialne Źródła Energii I Pojazdy Ekologiczne, WNT, Warszawa 2009.

[6] Wacławek M., Rodziewicz T., Ogniwa Słoneczne - Wpływ Środowiska Naturalnego na ich Pracę, WNT, Warszawa 2011.

\section{INSOLATION OF POLAND BASED ON NASA SATELLITE DATA}

\section{S u m m a r y}

Solar irradiation defines the amount of solar radiation which falls on specific surface in a given period of time. Due to this physical value one can estimate solar energy resources in a given time and place. This is especially important in the following sectors as agriculture, construction and energetics, wherever there is direct or indirect impact on finances. The value is a seemingly easy to measure, you only need an appropriate measuring equipment. The problem arises, however, when measurements cover a large area and the measuring devices are often not calibrated properly. Therefore it seems that the best solution would be using one type of devices, interconnected via special information network. The solution may be the measurement performed by satellites which are orbiting the earth. The content included herein is a trial to determine the conditions of insolation in Poland, by preparing analysis uses a database based on over 20 years of registration of solar radiation in the world by the satellite system, as part of NASA "Surface Meteorology and Solar Energy (SSE)." The measurements have a resolution of one degree of latitude and longitude.Calculations and their methodology contained in the article provided an opportunity to draw up a topology insolation for selected latitudes taking into account the relevant factors. The analysis results are shown in the drawings. Content of the drawings is dependent on the type of factor analyzed. The results of the analysis can serves in the planning of investments and modernization in Poland and affecting the effective management of solar energy for useful purposes.

Keywords: photovoltaics, algorithm, diffuse radiation, solar energy

Przestano do redakcji: 11.12.2014 $r$.

Przyjęto do druku: 22.06.2015 r.

DOI:10.7862/rb.2015.80 